\title{
The Innovative Solution of Typical Engineering Based on Function Model
}

\author{
Dongyan $\mathrm{Shi}^{1,2}$, Xianjie $\mathrm{Shi}^{2}$, and Cunyou Zhao ${ }^{3}$ \\ ${ }^{1}$ Postdoctoral Research Station of Instrument Science and Technology, Harbin University of \\ Science and Technology, 150080 Harbin, China \\ ${ }^{2}$ College of Mechanical and Electrical Engineering, Harbin Engineering University, \\ 150001 Harbin, China \\ ${ }^{3}$ Mechanical Engineering College Heilongjiang Institute of science and technology, \\ 150027 Harbin, China \\ \{shidongyan, shixianjie\}@hrbeu.edu.cn
}

\begin{abstract}
From the innovative perspective of the products, the function model of products and analysis are the basis of formulation of the innovative design. In order to solve this typical engineering problem, a function model of an actuator of shearer was constructed. Based on the foundation of function model analysis, the main problems of actuator of shearer productivity were clarified. An expression of contradictory conflict of helical drum was formulated using the creative technical method, i.e. the contradictory conflict theory. Furthermore, a creative design of helical drum was given to suggestion.
\end{abstract}

Keywords: Theory of inventive problem solving, shear, helical drum, function model.

\section{Introduction}

There is an ever increasing demand for the productivity of shearer by mine enterprises as the need of coals increased. The main problem of the shearer is its high energy consumption, and such problem belongs to the engineering design problems. Engineering design problems can be classified into three categories: big problems, middle problems and small problems [1-2]. The small problem refers to the gap between the current state and desired state of the existing products [3], and which can be solved by existing scientific technology. The theory of inventive problem solving (TRIZ) [4-6] has already provided a series of tools, such as inventive principles, separate principles matter-field analysis and standard solutions, in solving small problems. The high energy consumption of shearer belongs to one of the engineering small problems, and according to the process of design, it can be regarded as the mapping between the following four domains: requirement domain, function domain, structure domain and technology domain [7]. The main function of shearer is related to energy consumption of coal dropping and loading, and the corresponding structure to achieve the function is the helical drum of the shearer. This paper specifies the factors related to helical drum 
on the process of achieving its function by establishing the function model of the shearer helical drum, so as to provide the innovative solutions of low energy consumption and high efficiency of the shearer by applying the principles of TRIZ theory.

\section{Total Functions of Electrical Traction Shearer}

The general function of the system is, the shearer stripping down and shifting the coals on the wall while working, so that the movement of coal dropping and loading can be accomplished. The working principle is as follows: when electrical traction shearer works, it automatically adapts to the condition of load, and can strip down and shift coal while it is not to be overloaded.

The power and productivity of the shearer are mainly related to actuator. Coal is stripped down and shifted by drive components when executing agency received the signals of movement of coal dropping and loading.

Cutting unit and transmission are the main parts of actuator, and the work is done by helical drum. Helical drum which is the working mechanism of shearer is directly related to productivity and energy consumption. The structure of helical drum is shown in Fig.1.



1-Helical Vane 2-Section Disc 3-Tooth holder 4-Nuzzle 5-Drum Hub 6-Pick

Fig. 1. Helical drum

\section{Function Model of Helical Drum}

\subsection{Structure Model}

Function is implemented by substructure of system. Structure model of helical drum should first be made clear before function model is established. Such structure model contains table of component, structure matrix and table of structure. Structure matrix is shown as Fig.2, in which reciprocities of components are indicated. Black dots that indicate reciprocities are in the crossing of structure matrix. The reciprocities are not explained in Fig.2, while they are explained in Table 2. Table of components is shown as Table 1, within which the components of super-system, exist system and subsystem of helical drum are listed. 
Table 1. Assembly model of helical drum

\begin{tabular}{llll}
\hline $\begin{array}{l}\text { Components of } \\
\text { Super-system }\end{array}$ & Components of System & $\begin{array}{l}\text { Components of } \\
\text { Sub-system }\end{array}$ & $\begin{array}{l}\text { Effective } \\
\text { Object }\end{array}$ \\
\hline & Components of Pick & $\begin{array}{l}\text { Pick } \\
\text { Joint Part of Pick }\end{array}$ & $\begin{array}{l}\text { Coal Seam } \\
\text { Cutting Coal }\end{array}$ \\
Gas & Shell of Helical Drum & Helix Vane & \\
Air & & $\begin{array}{l}\text { Drum Hub } \\
\text { Tooth Holder }\end{array}$ & \\
Coal Dust & & Section Disc & \\
Spray Water & Nozzle & & \\
& Transmission & & \\
& System Connection & \\
& Spigot &
\end{tabular}

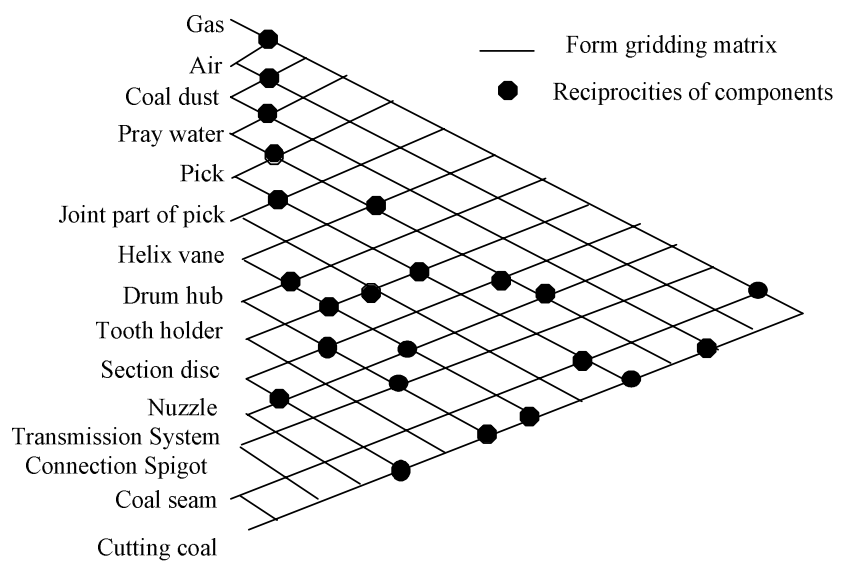

Fig. 2. Structure matrix of helical drum

Principle of establishing the structure model:

(1) Establishing the connection between technology system and super-system in special context;

(2) It could be listed by table or matrix;

(3) Establishing structure model of component model on each stage of the technology system lifecycle, and the components are related to helical drum;

(4) Connections of field and material are marked out;

(5) Analyze the effect of interactions between components, and the useful effect is marked by "+", the harmful effect is marked by ".-";

(6) The unrelated components are deleted. 
Table 2. Function concourse of helical drum

\begin{tabular}{|c|c|c|c|}
\hline $\begin{array}{l}\text { Serial } \\
\text { Number }\end{array}$ & $\begin{array}{l}\text { Relation } \\
\text { Components } 1\end{array}$ & Interaction & $\begin{array}{l}\text { Relation } \\
\text { Components } 2\end{array}$ \\
\hline 1 & Gas & $\begin{array}{l}\text { + Air contains gas } \\
\text { - Gas interfuses the air to form } \\
\text { dangerous explosive gases }\end{array}$ & Air \\
\hline 2 & Coal Dust & $\begin{array}{l}\text { + Air accommodate coal dust } \\
\text { - Coal dust interfuses the air to } \\
\text { form the foul gas }\end{array}$ & Air \\
\hline 3 & Pick & $\begin{array}{l}\text { + Pick link pieces fix pick } \\
\text { - Pick fray pick link pieces }\end{array}$ & Pick Link Pieces \\
\hline 4 & Helix Vane & + Drum wheel locate helix vane & Drum Wheel \\
\hline 5 & Tooth holder & + Helix vane locate tooth holder & Helix Vane \\
\hline 6 & Tooth holder & $\begin{array}{l}+ \text { Tooth holder space pick link } \\
\text { pieces }\end{array}$ & Pick Link Pieces \\
\hline 7 & Pick & $\begin{array}{l}\text { + Tooth holder location pick } \\
\text { - Pick fray tooth holder }\end{array}$ & Tooth holder \\
\hline 8 & Spray Water & $\begin{array}{l}\text { + Section disc supply spray water } \\
\text { channel } \\
\text { - Spray water erode section disc }\end{array}$ & Section Disc \\
\hline 9 & Section Disc & + Drum wheel locate section disc & Drum wheel \\
\hline 10 & Nozzle & + Helix vane locate nozzle & Helix Vane \\
\hline 11 & Section Disc & + Section disc locate nozzle & Nozzle \\
\hline 12 & $\begin{array}{l}\text { Transmission } \\
\text { System } \\
\text { Connection Spigot }\end{array}$ & $\begin{array}{l}+ \text { Drum wheel is supplied by } \\
\text { transmission system connection } \\
\text { spigot }\end{array}$ & Drum wheel \\
\hline 13 & Spray Water & $\begin{array}{l}\text { + Channel is supplied by nozzle } \\
\text { - Spray water fray nozzle }\end{array}$ & Nozzle \\
\hline 14 & Spray Water & $\begin{array}{l}\text { + Helix vane supply channel to } \\
\text { spray water } \\
\text { - Spray water fray helix vane }\end{array}$ & Helix vane \\
\hline 15 & Spray Water & $\begin{array}{l}+ \text { Spray water cold pick to } \\
\text { prevent sparkle cause gas } \\
\text { explosion when pick cut coal }\end{array}$ & Pick \\
\hline 16 & Coal Dust & $\begin{array}{l}+ \text { Spray water put out coal dust } \\
\text { that comes from cutting coal }\end{array}$ & Spray Water \\
\hline 17 & Cutting Coal & - Cutting coal fray section disc & Section Disc \\
\hline 18 & Coal Seam & - Coal seam release gas & Gas \\
\hline 19 & Coal Seam & $\begin{array}{l}\text { + Pick break out coal seam } \\
\text { - Coal seam fray pick }\end{array}$ & Pick \\
\hline 20 & Cutting Coal & $\begin{array}{l}+ \text { Drum wheel support cutting } \\
\text { coal }\end{array}$ & Drum Wheel \\
\hline 21 & Cutting Coal & $\begin{array}{l}\text { - Cutting coal fray drum wheel } \\
\text { - Cutting coal cause coal dust }\end{array}$ & Coal Dust \\
\hline 22 & Cutting Coal & $\begin{array}{l}+ \text { Helix vane push cutting coal } \\
\text { into scraper conveyor } \\
\text { - Cutting coal fray helix vane }\end{array}$ & Helix Vane \\
\hline 23 & Cutting Coal & - Cutting coal fray pick & Pick \\
\hline
\end{tabular}




\subsection{Establishment of Function Model}

Function model could be expressed by several methods, in which decomposition of function is expressed by function structure tree. Embryonic form of function model is established by considering the structure of upper sub-function. Then a perfect function structure chart is obtained by thinning the embryonic form layer by layer [8]. But the connection between function structures could not be expressed in this method. Another method which contains components and verbs is brought out to establish function model by Japanese scholars, and the verb indicates interaction with components. Function model of helical drum is established based on structure model in the later method, as is shown in Fig.3.

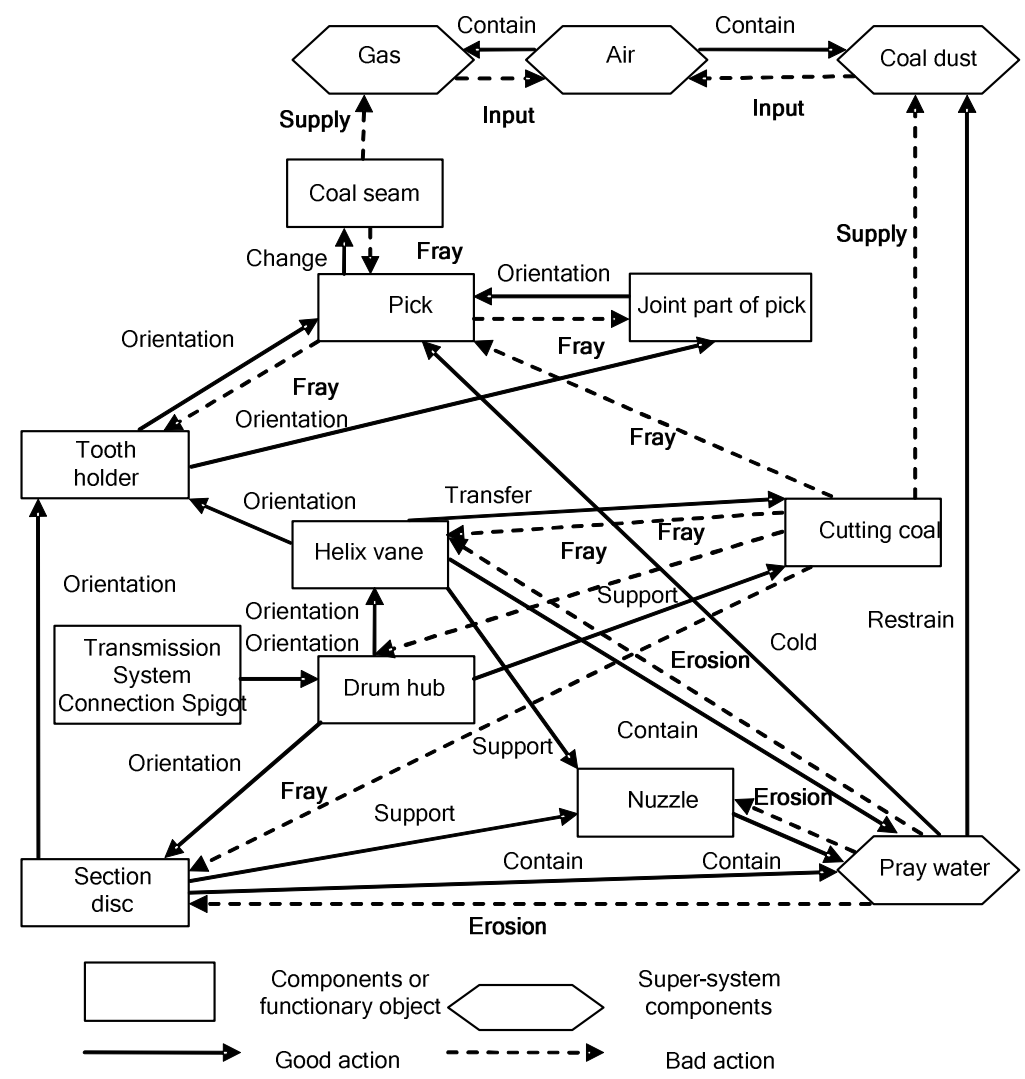

Fig. 3. Function model of helical drum

\section{Function Analysis of Shearer's Helical Drum Based on TRIZ}

\subsection{Key Reason Analysis of Energy Consumption}

The main problem in energy consumption is how to save more power on cutting drum, because 80 90\% power is used up on cutting drum when shearer works [9]. 
Energy flow of cutting drum is analyzed so that it is made sure which component takes part in energy consumption and which component uses up more energy in the end. Energy flow of cutting drum is shown in Fig. 4 as function model of helical drum. It is clear that the pick of helical drum need to be improved.

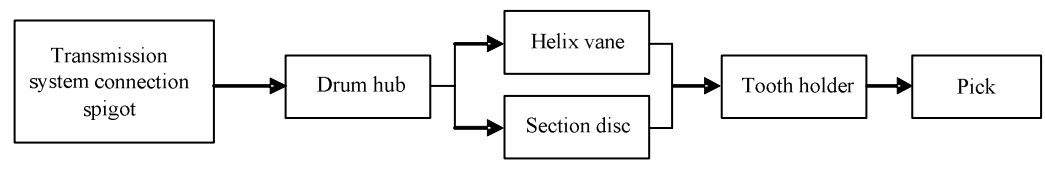

Fig. 4. Energy flow of helical drum

The energy consumption of shearer is mainly decided by cutting drum. The high energy consumption of pick, high energy consumption of drum and inflexible rotation of drum are the three main flaws. The reason analysis is shown as Fig.5.



Fig. 5. Reason-result analysis frame of helical drum's energy exhaust

\subsection{Contradictory Expression and Innovative Solution of Helical Drum}

All reasons could be listed by the causal analysis of helical drum energy consumption. It is that the configuration of picks that impacts the energy consumption. If picks are arranged intensively, the helical drum takes large energy consumption but the cutting edge is small; if picks are arranged sparsely, the helical drum takes small energy consumption but the cutting edge is big. According to the theory of TRIZ, the physical conflict of this engineering problem is composed.

The characteristics that are hoped to be improved and the characteristics that bring negative effect are determined by $39 * 39$ matrixes and 40 theories, which are shown in Table 3. By looking up the table of TRIZ conflict matrixes $[10,11]$, the four creating principles_35, 10, 38, 19, which resolved this conflict problem can be obtained. The corresponding four creative methods are: periodic effects, pre-operation, accelerate strong oxidizing, parameter variation. Pre-operation method is selected as solving theory of technical contradiction of cutting drum. Here there is not too much analysis in this paper due to the limited space. 
Table 3. Conflict matrix

\begin{tabular}{lllll}
\hline Theory & \multicolumn{4}{l}{ 20 Energy Consumption of Object } \\
\hline 39 Productivity & 35 & 10 & 38 & 19 \\
\hline
\end{tabular}

\subsection{Innovation Solution of Conflict of Helical Drum}

Deep coal seam is squeezed from three-direction by wall rock's action when coal is cut off by helical drum. Tensile strain is caused in bare surface along $\mathrm{X}$ axis direction, and it is called compression-tension. In area of compression-tension, joint fissures of coal seam increase, cutting impendence reduce, so that cutting force and energy component of cutting mechanism is reduced. The depth-web of helical drum is designed to make the full use of coal's compression-tension effect.

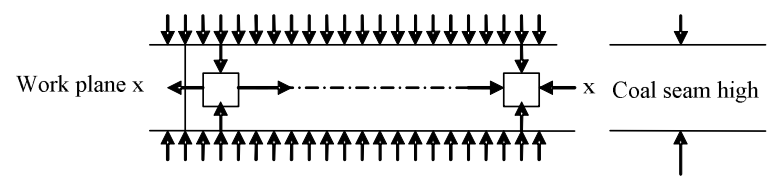

(a)



(b)

Fig. 6. Coal's compression-tension effect

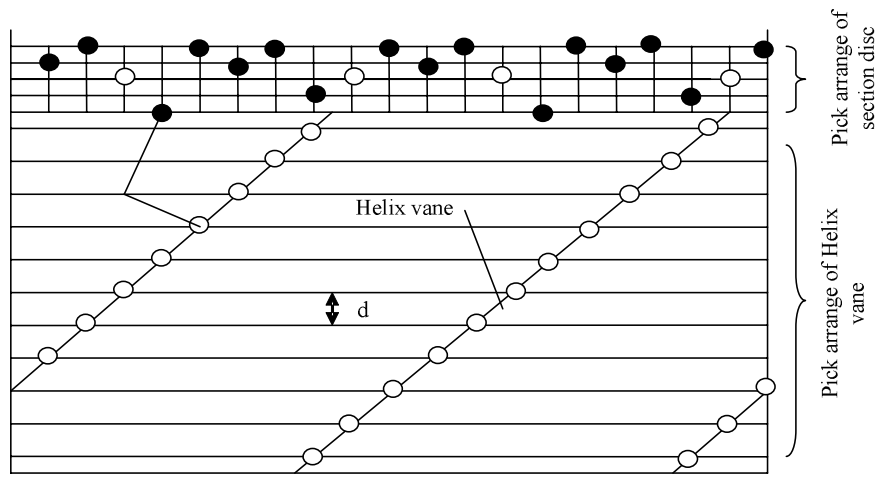

Fig. 7. Pick arrange drawing 
In order to give consider to the worse condition of cutting far from coal seam, picks of drum section disc are arranged intensively. Picks are also arranged as compression-tension effect; Picks of helical vane are arranged sparsely, and they are arranged along vane's helix. Arrange of picks in helical drum is shown as pick arrange drawing which is the spread picture of column cylinder of pick tine. Typical pick arrange drawing is shown as Fig.7. The circle is 0 degree fixing pick, while the macula is not 0 degree fixing pick. So the creative solution of pick arrange can be got.

\section{Conclusions}

Formulating a function model of shearer helical drum is the basis for solving the small problem in application of existing products of shearer. This is a systematic method of modeling the existing products. This function model not only can be used directly but also can be treated as the input of Pro/innovator, typical TRIZ software, and it can provide a valid example for other products' function model. At the same time, innovation solution of picks configuration is achieved based on analysis of shearer helical drum function model using TRIZ contradictory conflict theory. It can solve the problems of coal mining, such as large energy consumption and low efficiency. Further research will be focused on energy consumption and efficiency study according to TRIZ to get the optimized structure.

\section{Acknowledgments}

This work was supported by Natural Science Foundation of Heilongjiang Province of China No. E200819.

\section{References}

1. Savransky, S.D.: Engineering of Creativity. CSC Press, New York (2000)

2. Pahl, G., Beitz, W.: Engineering Design. London: the design council, 186-188 (1984)

3. Marconi, J.: ARIZ: The Algorithm for Inventive Problem Solving, an Americanized Learning Framework. TRIZ Journal (1998)

4. Altshuller, G.: The Innovation Algorithm. Worcester: Technical Innovation center (1999)

5. Gahide, S.: Application of TRIZ to Technology Forecasting Case Study: Yarn Spinning Technology. TRIZ Journal (July 2000)

6. Moehrle, M.G.: What is TRIZ? From conceptual basics to a framework for research. Creativity and Innovation Management 14, 3-13 (2005)

7. Suh, N.P.: Design Axioms and Quality control. Robotics \& Computer-integrated Manufacturing 9, 367-376 (1992)

8. Tan, R.H.: Innovative Design-TRIZ: The Invention Problem Solving. Machine Industry Publishing Company, China, Beijing (2002) (in Chinese)

9. Wang, Q., Li, B., Huang, J.: Mining Machinery and Timbering Equipment, vol. 50, pp. 110-111. China University of Mining and Technology Press (2006)

10. Belski, I.: Solving Problems with Method of the Ideal Result. TRIZ Journal (1999)

11. Altshuller, G.: And suddenly the inventor appeared, TRIZ, the Theory of Inventive Problem Solving. Technical Innovation Center, Massachusetts (1996) 